\section{Attempted Low-Temperature Syntheses of Kaolin Minerals}

ALTHOUGH kaolin minerals appear to be formed in Nature under acidic conditions at relatively low temperatures and low water-vapour pressures, their synthesis in the laboratory under similar conditions has been found exceptionally difficult. It appears that a proper choice of many variables is essential. In previous investigations ${ }^{1,2}$, individual kaolinite crystals have been obtained by ageing mixed alumina and silica gels for 2 months at $100^{\circ} \mathrm{C}$. and under $p \mathrm{H}$ conditions around $4 \cdot 5$, but the crystalline yield was extremely poor and the kaolinite could be proved only by single-crystal, electron diffraction methods; $\mathrm{X}$-ray diffraction failed to detect the small yield. It seems that the ready polymerization of silica, with aluminium incorporated in the structure, inhibited the crystallization of a layer structure. Similar difficulties are not encountered in forming hydrous magnesian silicates.

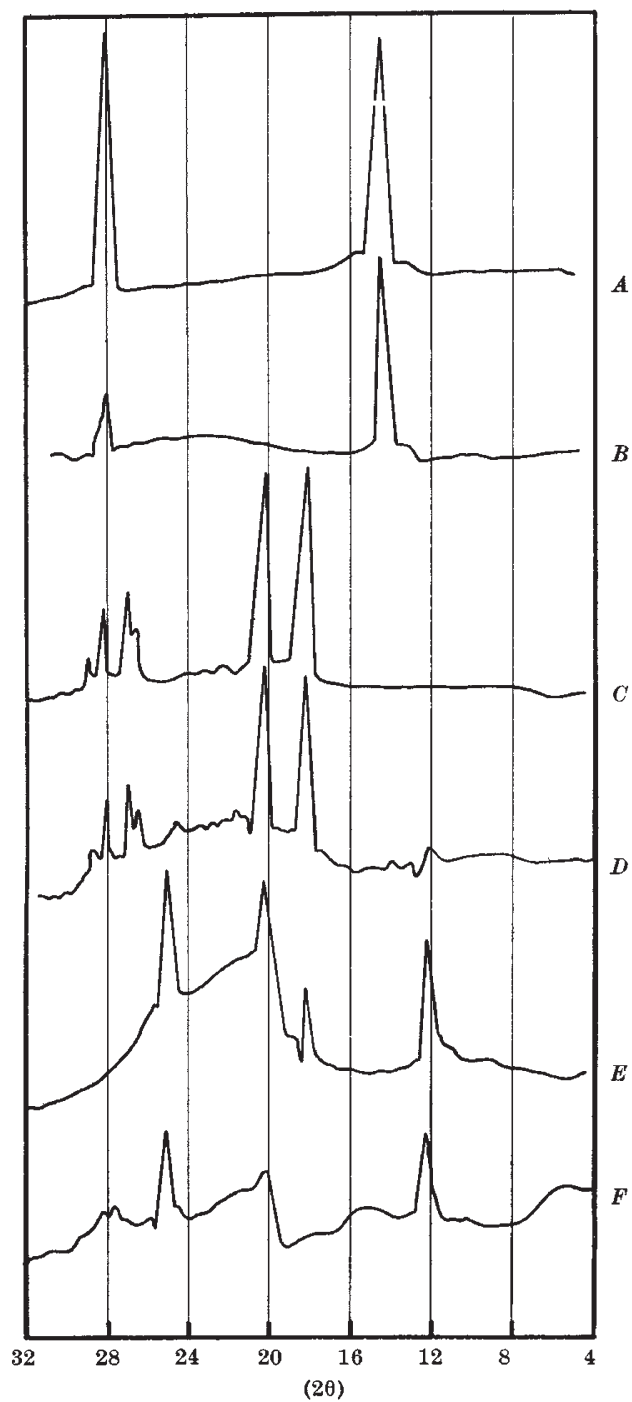

Fig. 1. X-ray diffractometer patterns; copper $K \alpha$ radiation. $A$, boehmite ; $B$, boehmite obtained from gibbsite in sealed tube at $150^{\circ} \mathrm{C}$. : $C$, gibbsite; $D$ and $E$, gibbsite partially transformed
In the present experiments, gibbsite, $\mathrm{Al}(\mathrm{OH})_{3}$, has been used as a source of alumina, together with silica either as a gel, 'Ludox', or in solution as ethyl silicate. The experiments have been conducted in sealed glass tubes at $150^{\circ} \mathrm{C}$. and about $5 \mathrm{~atm}$. watervapour pressure, and with vigorous end-over-end agitation. The $p \mathrm{H}$ was controlled mainly by $N / 10$ hydrochloric acid, but in experiments lasting 1-3 weeks the $p \mathrm{H}$ value often varied and a better control is desirable.

The results are illustrated in Fig. 1 by diffractometer diagrams. When the final $p \mathrm{H}$ exceeds $\mathbf{1} \cdot \mathbf{9}$, gibbsite is the only crystalline phase observed (cf. diagram $C)$. When the $p H$ remains below $1 \cdot 5$, a kaolin mineral replaces the gibbsite (ef. diagrams $D, E, F$ ). Electron micrographs show plate-like forms and also rod-like forms having some resemblance to halloysite. Reversible swelling and shrinkage behaviour is readily followed by X-ray diffraction, and each cycle of operations seems to improve the crystal structure. Whereas gibbsite in the absence of silica becomes transformed to boehmite at $150^{\circ} \mathrm{C}$. under the conditions of the experiments (cf. diagrams $A$ and $B$; also ref. 3), in the presence of silica the formation of boehmite is completely inhibited. Probably the instability of the gibbsite structure facilitates its reaction with silica to develop an alumino-silicate layer structure.

Further experiments are in progress in which temperature and $p \mathrm{H}$ will be controlled with more precision. This investigation forms part of Project 55, sponsored by the American Petroleum Institute. G. W. BRINDLEY

Department of Ceramic Technology,

Pennsylvania State University University Park, Pa.

\section{Now at}

\section{DE KIMPE}

Laboratoire des Colloides des Sols Tropicaux,

I.N.E.A.C., Institut Agronomique, Heverle-Louvain, Belgium.

${ }^{1}$ Gastuche, M. C., and De Kimpe, C., Acad. Roy. de Belg., Bull. Cl. Sc., fifth Ser., 45, 1087 (1959).

${ }^{2}$ De Kimpe, C., Gastuche, M. C., and Brindley, G. W., Amer. Mineral (in the press).

${ }^{8}$ Ervin, jun., G., and Osborn, E. F., J. Geol., 58, 381 (1951).

\section{CRYSTALLOGRAPHY}

\section{Spiral Formation on Natural Crystalline Sulphur}

ReCentLy, observations of the growth spirals suggested by Frank's theory ${ }^{1}$ have been reported on many different substances.

This communication records some interesting observations of growth spirals originating from screw dislocations on the $(001)$ faces of natural sulphur crystals. The observations were made by means of an ordinary metallurgical microscope, using bright-field illumination. The heights of the steps were measured using interferometric techniques ${ }^{2}$ and the values found range from $5000 \AA$. to $100 \AA$., showing that growth-promoting dislocations are of multiple strength.

Most of the faces investigated showed one spiral only, covering the whole area, which seems to prove that sulphur crystals must be extremely perfect.

Fig. 1 shows a spiral originating from a right-handed dislocation. Besides this elementary type of spiral, several other more complicated growth patterns, for 